\title{
Pengaruh Efek Kapasitansi Bumi Terhadap Saluran Transmisi Circuit Ganda Jarak Jauh Pada Sistem Kelistrikan Sulawesi Selatan Dan Barat
}

\author{
Yusri Anugrah Manapa Ambabunga* \\ *Teknik Elektro, Fakultas Teknik, Universitas Kristen Indonesia Toraja, \\ yusriambabunga@ukitoraja.ac.id
}

\begin{abstract}
Penelitian ini bertujuan untuk menentukan pengaruh efek kapasitansi bumi pada saluran transmisi jarak jauh 3 phasa khususnya pada saluran transmisi ganda pada sistem kelistrikan Sulawesi Selatan dan Barat, bagaimana menentukan metode yang digunakan untuk pengolahan data jaringan sistem saluran transmis sirkuit ganda, menentukan besar kapasitas daya hantar saluran transmisi yang berbanding lurus dengan besarnya tegangan listrik saluran transmisi 3 phasa serta panjang saluran dan luas penampang saluran transmisi 3 phasa pada sistem kelistrikan Sulawesi Selatan Dan Barat. Dengan diperolehnya hasil pengolahan data jaringan sistem saluran transmisi sirkuit ganda maka akan mempermudah melakukan analisa desain dan rancangan sistem transmisi 3 phasa agar diperoleh keandalan sistem penyaluran daya dari pusat pembangkit ke pusat pusat beban dimana saluran transmisi 3 phasa menjadi penghubung keandalan sistem penyaluran daya dari pusat pembangkit ke pusat pusat beban sistem kelistrikan Sulawesi Selatan Dan Barat sebagai satu sistem yang saling terinterkoneksi dalam wilayah PLN VIII Sultanbatara.
\end{abstract}

\section{BAB I}

\section{PENDAHULUAN}

\section{Latar Belakang Masalah}

Untuk menyalurkan tenaga listrik dari pusat pembangkit sampai pada pusat 
Beban maka diperlukan jaringan mulai dari saluran transmisi sampai pada jaringan distribusi, sehingga di sekitar saluran transmisi maupun jaringan distribusi terdapat kuat medan magnet yang ditimbulkan oleh arus yang dialirkan oleh penghantar tersebut. Penggunaan saluran transmisi udara dengan tegangan ekstra tinggi diperoleh berbagai keuntungan. Sebagai contoh, dengan menggunakan tegangan tinggi maka daya yang disalurkan semakin besar sehingga dapat memperbaiki kerugian daya yang terjadi pada saluran transmisi. Namun disamping keuntungan, terdapat juga kerugian yang ditimbulkan oleh jaringan tegangan ekstra tinggi. Salah satunya adalah adanya medan magnet yang ditimbulkan oleh penghantar yang dialiri arus listrik. WHO ( World Health Organization) telah menentukan kuat medan magnet sebesar 240 A dalam Amplitudo/m tidak mengganggu manusia. Cara yang dapat dilakukan untuk meminimumkan kuat medan magnet tersebut antara lain dengan meninggikan jaringan transmisi atau merubah konfigurasi saluran transmisi serta memanfaatkan permukaan bumi untuk memperbesar nilai kapasitansi saluran transmisi. Daya listrik yang disalurkan semakin besar juga memungkinkan timbulnya medan magnet yang besar. Sehingga untuk menganalisa hal tersebut, penulis memilih judul penelitian yaitu : "Pengaruh Efek Kapasitansi Bumi Terhadap Saluran Transmisi Sirkuit Ganda Jarak Jauh Pada Sistem Kelistrikan Sulawesi Selatan “.

\section{Rumusan Masalah}

Dalam melakukan penelitian ini beberapa rumusan masalah dapat ditinjau :

1. Bagaimana menentukan metode yang digunakan pada pengolahan data jaringan sistem transmisi sirkuit ganda.

2. Bagaimana menentukan tegangan transmisi pada sistem saluran transmisi sirkuit ganda pada sistem kelistrikan Sulsel.

\section{Batasan Masalah}

Dalam penelitian ini penulis membatasi masalah pada :

1. Perhitungan parameter saluran transmisi

2. Perhitungan tegangan dan arus pada diagram pengganti saluran transmisi 
3. Pemilihan konfigurasi konduktor

4. Perhitungan rugi korona dan rugi daya aktif

\section{Tujuan Penelitian}

Adapun tujuan penelitian sebagai berikut :

1. Untuk Menentukan pengolahan data jaringan transmisi sirkuit ganda

2. Untuk mengetahui nilai parameter saluran transmisi sirkuit ganda

3. Untuk memahami efek kapasitansi bumi pada saluran transmisi ganda.

\section{Manfaat Penelitian}

Adapun manfaat penelitian sebagai berikut :

1. Memberikan data awal hasil pengolahan data jaringan transmisi sirkuit ganda Sulawesi Selatan khususnya saluran transmisi Makassar - Parepare

2. Bahan informasi bagi peneliti selanjutnya menyangkut data jaringan saluran transmisi listrik

\section{BAB II}

\section{TINJAUAN PUSTAKA}

\section{Pengertian Saluran Transmisi}

Saluran transmisi adalah saluran yang menyalurkan daya listrik dari pusat pembangkit ke pusat-pusat beban. Pusat pembangkit listrik (Electric Power Station), seperti: PLTA, PLTD, PLTU, PLTD dan lain lain, letaknya jauh dari pusat pusat beban (Load Centress). Saluran transmisi listrik mempunyai parameter parameter yang mempengaruhi tingkat kemampuan untuk berfungsi sebagai bagian dari sistem tenaga, yaitu : Resistansi (R), Induktansi(L) serta Kapasitansi (C)..

\section{a. Tahanan (R)}

Nilai tahanan suatu penghantar diberikan dalam persamaan :

$$
\mathrm{R}=\mathrm{P} \mathrm{L} / \mathrm{A}(\mathrm{Ohm})
$$


Dalam hal ini :

$$
\begin{aligned}
& \mathrm{P}=\text { Tahanan jenis penghantar }(\mathrm{Ohm} / \mathrm{m}) \\
& \mathrm{L}=\text { Panjang penghantar }(\mathrm{Km}) \\
& \mathrm{A}=\text { Luas penampang penghantar }\left(\mathrm{m}^{2}\right)
\end{aligned}
$$

Dari persamaan diatas dapat diketahui bahwa besarnya tahanan dari suatu kawat penghantar tergantung dari 3 faktor utama yaitu :

1. Induktansi ( L)

2. Resistansi (R)

3. Kapasitansi $(\mathrm{C})$

Komponen komponen utama saluran transmisi :

a. Kawat Penghantar Saluran Transmisi. Penghantar untuk saluran transmisi lewat udara dapat diklasifikasikan sebagai berikut :

1. $\mathrm{AAC}=$ All-Aluminium Conductor, yaitu : kawat penghantar yang seluruhnya terbuat dari aluminium

2. $\mathrm{AAAC}=$ All-Aluminium-Alloy Conductor, yaitu : kawat penghantar yang seluruhnya terbuat dari campuran aluminium

3. ACSR $=$ Aluminium Conductor, Steel-Reinforced, yaitu : Kawat penghantar aluminium berinti kawat baja.

4. $\mathrm{ACAR}=$ Aluminium Conductor, Alloy-Reinforced, yaitu : kawat penghantar aluminium yang diperkuat dengan logam campuran.

b. Menara Transmisi. Menara atau tiang transmisi adalah suatu bangunan penopang saluran transmisi, yang bisa berupa menara baja, tiang baja, tiang beton bertulang dan tiang kayu..Tiang tiang baja, beton atau kayu umumnya digunakan pada saluran transmisi dengan tegangan kerja relatif rendah ( dibawah $70 \mathrm{KV}$ ), sedang untuk saluran transmisi tegangan tinggi atau ekstra tinggi digunakan menara baja..Contoh menara transmisi tersebut :

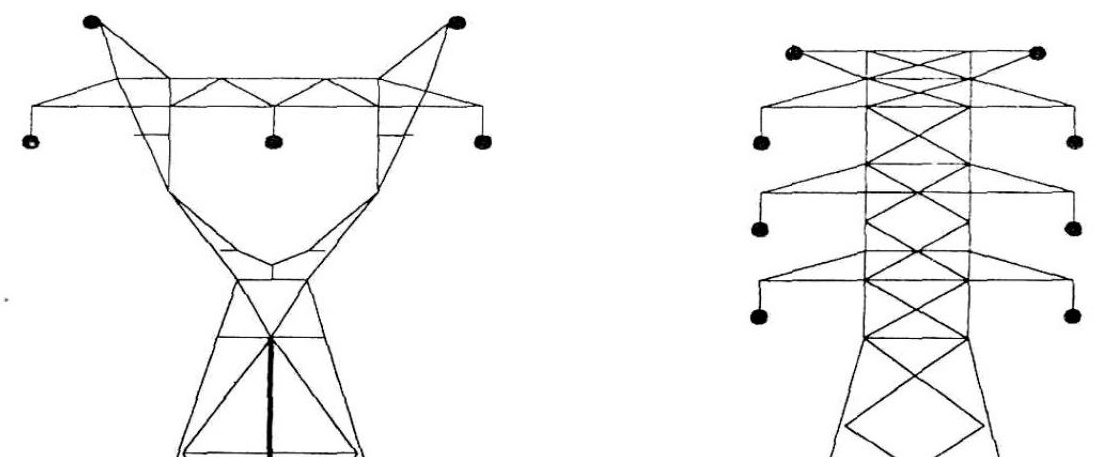




\section{c. Klasifikasi Saluran Transmisi :}

1. Saluran Transmisi menurut tegangan kerja.

Di Indonesia, telah diseragamkan deretan tegangan tinggi sebagai berikut

a. Tegangan nominal (KV) : $30-66-150-220-380-500$

b. Tegangan peralatan (KV) : $36-72,5-170-245-420-525$.

Penentuan deretan tegangan diatas disesuaikan dengan rekomendasi International Comissio (IEC). Tetapi di negara negara yang telah maju seperti Amerika Serikat, Canada, Rusia dan sebagainya, tegangan transmisi telah mencapi harga $500 \mathrm{KV}$ sampai $1000 \mathrm{KV}$. Di tempat tempat tersebut tegangan telah dikelompokkan sebagai berikut :
a. Tegangan tinggi, kurang dari $138 \mathrm{KV}$
b. Tegangan extra tinggi, antara $220-765 \mathrm{KV}$
c. Tegangan Ultra Tinggi, lebih dari $765 \mathrm{KV}$.

2. Saluran transmisi untuk keperluan diagram pengganti :
a. Saluran pendek ( dibawah $80 \mathrm{Km}$ )
b. Saluran menengah ( $80-250 \mathrm{Km})$
c. Saluran panjang ( diatas $250 \mathrm{Km}$ )

Diagram pengganti saluran transmisi :

1. Saluran Transmisi Pendek Dan Menegah

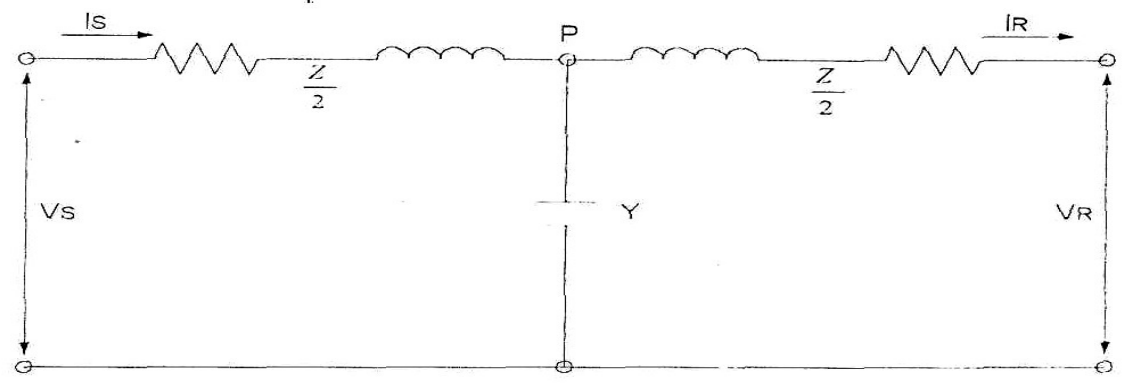


2. Saluran Transmisi Panjang Atau Jarak Jauh.

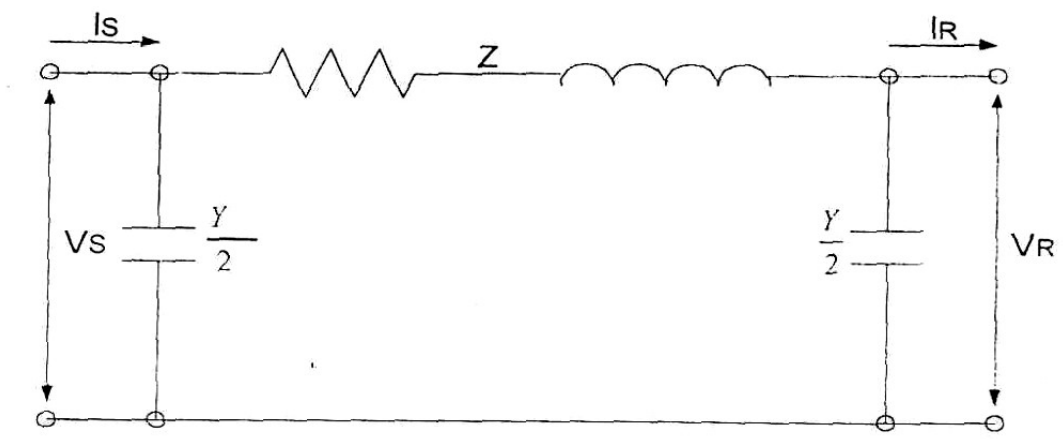

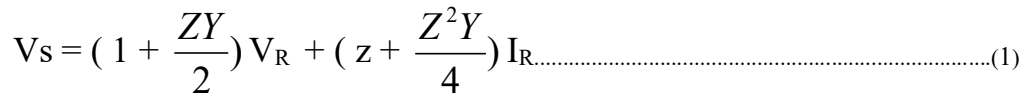

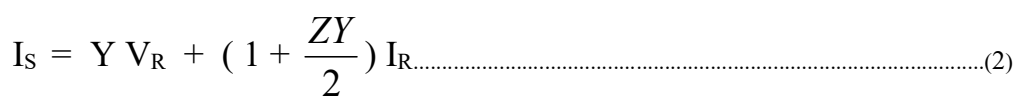

\section{c.Konfigurasi Konduktor/ Penghantar Transmisi}

Ada 6 macam pemodelan untuk konfigurasi konduktor yaitu :

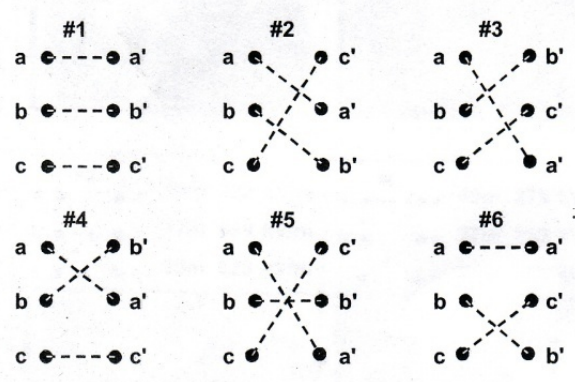




\section{BAB III \\ METODOLOGI PENELITIAN}

1. Waktu Dan Tempat Penelitian

a. Waktu Penelitian

Pelaksanaan penelitian dilakukan selama 3 bulan, yang berlangsung dari bulan Juli sampai September Tahun 2017, dengan agenda kegiatan tersusun dibawah ini :

1. Persiapan

2. Pengambilan data

3. Verifikasi data

4. Analisis data

5. Desiminasi data.

Dapat dilihat pada tabel dibawah ini :

\begin{tabular}{|l|l|l|l|}
\hline KEGIATAN & JULI 2017 & AGUSTUS 2017 & $\begin{array}{l}\text { SEPTEMBER } \\
\mathbf{2 0 1 7}\end{array}$ \\
\hline PERSIAPAN & Tgl $10-17$ & & \\
\hline $\begin{array}{l}\text { PENGAMBILAN } \\
\text { DATA }\end{array}$ & Tgl $19 \mathrm{~s} / \mathrm{d}$ & Tanggal 06 & \\
\hline VERIFIKASI DATA & & Tgl 08 - 15 & \\
\hline ANALISIS DATA & & Tgl $18 \mathrm{~s} / \mathrm{d}$ & Tanggl 02 \\
\hline DESIMINASI & & & Tgl $04-16$ \\
\hline
\end{tabular}

\section{b. Tempat Penelitian}


Penelitian ini dilakukan pada instansi PLN Unit AP2B (Area Penyaluran Dan Pengatur/Pengendali Beban ) Sistem PLN Wilayah VIII Sultanbatara ( Sulawesi Selatan, Barat dan Tenggara ), Makassar.

\section{c. Metode Pengumpulan Data}

Adapun metode pengumpulan data sebagai berikut :

1. Penelitian data pustaka ( Library Research )

2. Penelitian lapangan ( Field Research ) terbagi atas :

a. Observasi ( Pengamatan )

b. Wawancara ..

\section{d. Jenis Dan Sumber Data :}

1. Data Primer, yaitu data yang langsung diperoleh dari AP2B Sistem PLN Wilayah VIII Sultanbatara, Makassar, Sulawesi Selatan.

2. Data Sekunder, yaitu data yang diperoleh melalui penelitian sebelumnya antara lain : Jurnal, buku cetak, dsbainya.

\section{e. Metode Analisis}

Dalam menyelesaikan perhitungan data impedansi, digunakan rumus dan konstanta parameter saluran transmisi R,L,C sebagai berikut :

1. $\mathrm{R}=\mathrm{P} \mathrm{L} / \mathrm{A}(\mathrm{Ohm})$

2. $\mathrm{L}=2 \times 10^{-7} \ln \mathrm{D}_{\mathrm{eq}} / \mathrm{D}$ ( Henry ) per phasa

3. $\mathrm{Cn}=2 л \mathrm{~K} / \ln \left(\mathrm{D}_{\text {eq }} / \mathrm{D}_{\mathrm{sc}}\right)($ farad $)$ ke netral (titik nol $)$.

Pada perhitungan relasi arus ( I ) dan Tegangan (V) dibagi menjadi 2 saluran diagram pengganti, yaitu :

a. Saluran pendek :

$$
\begin{aligned}
& \mathrm{Is}=\mathrm{PR} / \sqrt{ } 3 . \mathrm{VR}(\mathrm{L}-\mathrm{L}) \cdot \mathrm{pf} \\
& \mathrm{Vs}=\mathrm{V}_{\mathrm{R}}+\mathrm{Z} \cdot \mathrm{I}_{\mathrm{R}}
\end{aligned}
$$

b. Saluran menengah, digunakan dua referensi, yaitu :

1. Berdasarkan Nominal T (tee) :

$$
\begin{aligned}
& I s=Y V_{R}+V_{R} \\
& V_{S}=(1+Z Y / 2) V_{R}+(Z+Z Y / 4) I . R .
\end{aligned}
$$


2. Berdasarkan nominal phi, yaitu :

$$
\begin{aligned}
& \mathrm{Is}=(1+\mathrm{ZY} / 4) \mathrm{YVR}+(1+\mathrm{ZY} / 2) \mathrm{IR} \\
& \mathrm{Vs}=(1+\mathrm{ZY} / 2) \mathrm{VR}+\mathrm{ZIR} .
\end{aligned}
$$

\section{BAB IV}

\section{HASIL DAN PEMBAHASAN}

\section{Menghitung Parameter Saluran Transmisi}

a. Menghitung Tahanan / Resistansi ( R ).

Yang dimaksud dengan nilai tahanan / resistansi disini adalah resistansi efektif. Resistansi efektif sama dengan resistansi arus searah (DC) dari saluran jika terdapat distribusi arus yang merata ( seragam /uniform) di seluruh penghantar.

Tahanan arus searah yang diperoleh dari tabel harus dikalikan dengan faktor koreksi :

1,0 untuk konduktor padat ( solid Wire )

1,01 untuk konduktor pilin yang terdiri dari 2 lapis (strand)

1,02 untuk konduktor pilin lebih dari 2 lapis.

Untuk perhitungan saluran transmisi digunakan faktor koreksi 1.02 sehingga bila konduktor bekerja pada temperatur $25^{\circ} \mathrm{C}$ untuk aluminium dengan konduktivitas $61 \%$ maka tahanan arus searahnya (DC) adalah :

$\mathrm{R}_{25}=\mathrm{P}_{25} \mathrm{l} / \mathrm{A}(\mathrm{Ohm})$

$\mathrm{P}_{25}=2,89$ mikro $-\mathrm{ohm}-\mathrm{cm}=2,89 \times 10^{-6}$ mikro-km

$\mathrm{A}=152 \mathrm{~mm}^{2}=152 \times 10^{-2} \mathrm{~cm}^{2}$

$\mathrm{L}=135.30 \mathrm{Km}=135.30 \times 10^{5} \mathrm{~cm}$

$\mathrm{R}_{25}=1.02 \times 2.89 \times 10^{-6} \times 135.30 \times 10^{5} / 152 \times 10^{-2}$

$=26.23 \mathrm{Ohm}$ per $\mathrm{Km}$

Jadi pada temperatur $25^{\circ} \mathrm{C}$, nilai resistansi dari konduktor tersebut adalah 26.23 Ohm per Km per kawat penghantar tersebut.

b. Menghitung Induktansi ( L )

Rumus Induktansi : $\mathrm{L}=2 \times 10^{-7} \ln \mathrm{D}_{\mathrm{eq}} / \mathrm{D}$ ( Henry ) / per phasa 
Dalam hal ini kita menghitung nilai induktansi dari saluran tiga phasa dan yang bekerja pada frekwensi 50 Hertz.

Perhitungannya sebagai berikut :

$\mathrm{D}_{\mathrm{s}}=0.1933 \mathrm{Km}$

Jarak a ke $b=\sqrt{ }\left(10^{2}+1.5^{2}\right)=10.1 \mathrm{~m}$

Jarak a ke $b^{\prime}=\sqrt{ }\left(10^{2}+19.5^{2}\right)=21.9 \mathrm{~m}$

GMD antara phasa ke phasa adalah :

$\mathrm{Dab}=\mathrm{Dbc}=4 \sqrt{ }\left(10.1^{2}+21.9^{2}\right)=14.88 \mathrm{~m}$

$\operatorname{Dcd}=4 \sqrt{ }\left(20^{2}+18^{2}\right)=18.97 \mathrm{~m}$

$\operatorname{Deq}=3 \sqrt{ }-(14,88 \times 14,88 \times 18.97)^{2}=16.1$ meter.

c. Menghitung Kapasitansi ( C )

Rumus Kapasitansi : $\mathrm{Cn}=2 \pi \mathrm{k} / \ln \left(\mathrm{D}_{\text {eq }} / \mathrm{D}_{\mathrm{sc}}\right)$ ( farad $)$ ke netral

Persamaan persamaan induktansi dan Kapasitansi pada dasarnya memiliki kemiripan. Suatu metode GMD yang disesuaikan ternyata berlaku juga untuk menentukan kapasitansi saluran penghantar berkas jenis ACSR Ostrich 300.000 Cmil 26/7, memiliki jari jari luas penghantar $=0.680 \mathrm{~m}$, digunakan sebagai GMR nya..

$\mathrm{r}=0.680 / 2 \mathrm{x} \mathrm{I} 2=0.0283 \mathrm{~m}$

$\mathrm{D}_{\text {eq }}=16.1 \mathrm{~m}$

$\mathrm{D}_{\mathrm{sc}}=(\sqrt{ } 26.9 \times 0.0283 \sqrt{ } 21 \times 0.0283 \sqrt{ } 26.9 \times 0.0283)^{1 / 3}$

$=0.837 \mathrm{~m}$

$\mathrm{C}_{\mathrm{n}}=2 \pi \mathrm{k} / \ln \left(\mathrm{D}_{\mathrm{eq}} / \mathrm{D}_{\mathrm{sc}}\right)($ Farad $)$

$=2$ л $\left(8.854 \times 10^{12}\right) / \ln (16.1 / 0.837)=18.807 \times 10^{-12} \mathrm{~F} / \mathrm{m} .$.

Untuk Susepstansi kapasitifnya pada frekuensi 50 Hertz :

$\mathrm{B}_{\mathrm{c}}=1 / 2$ л $50 \times\left(18.807 \times 10^{12}\right) \times 1609$

$=9.5 \times 10^{-6} \mathrm{Ohm}$ per meter per fasa ke netral.

\section{BAB V}

\section{KESIMPULAN DAN SARAN}




\section{Kesimpulan}

Dari hasil perhitungan data data yang dilakukan, maka dapat disimpulkan bahwa :

a. Hasil yang diperoleh sebagai berikut : $\mathrm{R}=26.23 \mathrm{Ohm} / \mathrm{km}, \mathrm{L}=3.99 \times 10^{-7}$ $\mathrm{H}$ per meter per phasa ( untuk nilai induktansi terendah ) dan $\mathrm{L}=4.26 \times 10^{-7}$ $\mathrm{H} / \mathrm{m}$ per fasa ( untuk nilai induktansi tertinggi ), $\mathrm{C}=18.807 \times 10^{-12} \mathrm{~F} / \mathrm{m}$, nilai R,L,C tersebut masih normal untuk kestabilan daya serta tegangan listrik yang disuplai dari pusat beban ke konsumen. Dalam hal ini, kita mengabaikan nilai nilai yang sering berubah akibat adanya nilai rugi rugi daya dan arus bocor..

b. Tegangan dan arus pada sistem transmisi sirkuit ganda pada sistem kelistrikan Sulawesi Selatan Dan Barat sangat dipengaruhi oleh nilai efek pengaruh kapasitansi bumi terhadap perubahan medan magnet listrik pada kawat transmisi dalam hal mempertahankan kuantitas penyaluran daya listrik dari pusat pusat pembangkit menuju ke pusat pusat beban listrik 3 phasa.

\section{Saran}

a. Nilai kapasitansi dari hasil perhitungan relatif kecil untuk mempertahankan faktor daya beban, maka disarankan untuk memasang kapasitor kompensasi.

b. Disarankan untuk meninggikan tegangan transmisi untuk mengurangi rugi rugi daya dan arus bocor, selain itu luas penampang konduktor harus diperbesar hingga batas batas tertentu.

c. Disarankan untuk mengatur letak konduktor dengan jarak diagonalnya 1.5 sampai $3 \mathrm{~m}$, serta ketinggiannya dari permukaan bumi sekitar $15 \mathrm{~m}$ sampai $20 \mathrm{~m}$.

\section{DAFTAR PUSTAKA}

1. Arismunandar, A. 1993, “ Buku Pegangan Teknik Tenaga Listrik ( Jilid kedua) Saluran Transmisi “, Pradya Paramita, Jakarta.

2. Gonen, T, 1998, “ Electric Power Transmission System Engineering “, Wiley Interscines Publition, John Wiley Sons Inc, Canada. 
DYNAMIC SAINT

JDS, Jilid III no. 1, Oktober 2017

3. Hutauruk, T.S., 1993, “Transmisi Daya Listrik”, Erlangga .

4. Marsudi, D, 1990, “ Operasi Sistem Tenaga Listrik”, Balai Penerbit Dan Humas ISTN, Jakarta.

5. Wardahana, W, 1997, “ Masalah Radiasi Tegangan Tinggi “, Ganesha Exact Bandung. 